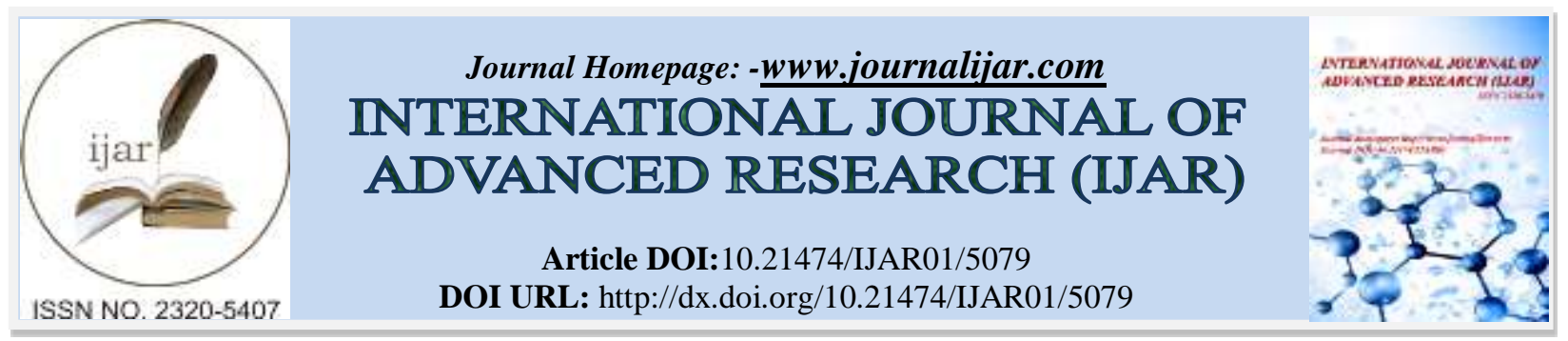

RESEARCH ARTICLE

\title{
LEAD NITRATE INDUCED DEVELOPMENTAL DEFECTS IN DROSOPHILA MELANOGASTER ACCOMPANIED WITH LARVAL CHROMOSOMAL REARRANGEMENTS.
}

\author{
Ashim Kumar Basak ${ }^{1}$, Tridip Chatterjee ${ }^{2}$, Arijit Sarbabidyaa ${ }^{3}$ and Amit Chakravarty ${ }^{4}$. \\ 1. Associate Professor \& Head, Department of Molecular Biology, Institute of Genetic Engineering 30, Thakurhat \\ Road,Kolkata-700128, India. \\ 2. Assistant Professor, Department of Molecular Biology, Institute of Genetic Engineering 30, Thakurhat Road, \\ Kolkata-700128, India. \\ 3. Department of Genetics, Institute of Genetic Engineering 30, ThakurhatRoad ,Kolkata-700128, India. \\ 4. Director, Institute of Genetic Engineering, 30 Thakurhat Road, Kolkata-700128, West Bengal.
}

\section{Manuscript Info}

(..........................

Manuscript History

Received: 05 June 2017

Final Accepted: 07 July 2017

Published: August 2017

Key words:-

Lead nitrate, Drosophila melnogaster,

larva, pupa Chromosomal aberration,

ectopic pairing, asynapsis.

\section{Abstract}

Lead induced toxicity is common in human due to repeated occupational exposure of this heavy metal as well as its incorporation into the body through contaminated food and environmental pollutions. With a view to assess toxic potential of this heavy metal on development, dose dependent exposures of lead nitrate was given to a model organism, Drosophila melanogaster during its development. It was observed that at low doses lead nitrate did not affect the development of this fly. However, beyond at certain concentration, it exerted negative influences on its metamorphosis as well as in the number of pupa and emerging adults accompanied with various chromosomal abnormalities in third instar larval polytene chromosomes. From our experimental results it can be suggested that lead nitrate induced chromosomal abnormalities in larvae may cause dysfunction of developmental genes that give rise to developmental delay and reduce the the population of emerging individuals. As Drosophila melanogaster exhibit subtantial similarities with human genome, negative developmental outcome owing to a lead salt exposure in this fly may reflect analogous situation during human pregnancy.

Copy Right, IJAR, 2017,. All rights reserved.

\section{Introduction:-}

Lead $(\mathrm{Pb})$ is a toxic and the most abundant heavy metal in nature. It occurs naturally in the earth's crust but various human activities such as mining, burning fossil fuels, manufacturing etc. has caused its widespread distribution and mobilization in the environment (Tong et.al. 2000; www.mayoclinic.org). Owing to its continuous uses, level of $\mathrm{Pb}$ rises in almost every country and becomes highly persistant in the environment. Various occupations like those deal with smelting of $\mathrm{Pb}, \mathrm{Pb}$ based painting, $\mathrm{Pb}$ containing pipes, battery recycling, pigments, pottery etc. cause toxic exposure of this element to human (Wani et al, 2015). Effects of $\mathrm{Pb}$ are same whether it is inhaled or taken orally and correlated with blood $\mathrm{Pb}$ level (Abadin et al, 2007). Apart from occupational lead exposures and inhalation of air containing lead resulted from the combustion of lead containing fossil fuels, this heavy metal can also get access in the human body from foods and soil ( $\mathrm{Lu}$ et al , 2015). Lead exposure through drinking water occurs mainly due to 
its presence in older pipes, solders and fixtures (Abadin et al, 2007). Children are more susceptible to lead exposure as they put hands, toys and other materials contaminated with lead containing dirts in their mouth (Agrawal et al, 2009). Adverse effects of $\mathrm{Pb}$ poisoning in human include irreversible brain damage, damages in liver, kidney and gastrointestinal system, mental retardation and intellectual deficiencies in children, developmental delay, fatal infant encephalopathy(Abdullahi, 2013; Safaee et al, 2014) as well as many forms of cancer (https://ntp.niehs.nih.gov/ntp/roc/content/profiles/lead ). A number of water soluble and water insoluble $\mathrm{Pb}$ compounds that are used in various industries increase the chances of lead toxicity in human. For example, soluble lead compounds such as lead acetate, lead acetate hydrate, lead nitrate are used in cotton dyes, varnishes and in the manufacture of matches and explosives respectively. Insoluble lead compounds such as lead azide, lead carbonate, lead fluoride, lead phosphate are used in manufacturing military weapons, contigs for thermographic copying, electronic industries and plastic industries respectively (https://ntp.niehs.nih.gov/ntp/roc/content/profiles/lead). Pb can cross the placental barrier as it has been found to be present in the fetal tissues and exhibited negative developmental outcomes such as spontaneous abortion and still birth (Amadi et al, 2017). Although lead toxicity in animals is well known (Assi et al, 2016), dose dependent effects of this heavy metal is imperative to understand its toxic potential. Comparartive analysis of whole genome sequence established that nearly $75 \%$ of the human diseaserelated genes have functional homologs in this fly (Pandey et al, 2011 ). Due to such extensive genetic homology between human and Drosophila, it seems possible that in vivo health related experimental results obtained from this eukaryote may correspond to similar situations in humans. In fact a number of experiments have been carried out to assess the effects of some lead salts on the developmental outcome of Drosophila melanogaster in dose dependent manners(Haq et al, 2011; Safaee et al, 2014). However, no report is still available regarding the dose dependent effect of any lead salt on the development and simultaneous susceptibility of chromosomes at any particular stage of development of this fly. Thus in this present study an attempt has been made to understand the dose dependent effects of a lead salt, lead nitrate $\left(\mathrm{Pb}\left(\mathrm{NO}_{3}\right)_{2}\right)$, on the development of Drosophila melanogaster and to assess the simultaneous effect of different doses of this heavy metal salt on polytene chromosomal architechture at the third instar larval stage of this fly.

\section{Material and methods:-}

\section{Chemicals:-}

Lead nitrate $\left(\mathrm{Pb}\left(\mathrm{NO}_{3}\right)_{2}\right)$, Nice Chemicals, India), agar, sodium chloride ( $\mathrm{NaCl}$, Sisco Research Laboratories, India), potassium chloride ( $\mathrm{KCl}$, Sisco Research Laboratories, India), calcium chloride $\left(\mathrm{CaCl}_{2}\right.$, Sisco Research Laboratories, India), yeast (Kothari fermentation and biochem Ltd, India), glacial acetic acid $\left(\mathrm{CH}_{3} \mathrm{COOH}, \mathrm{Sisco}\right.$ Research Laboratories, India), propionic acid ( $\mathrm{CH}_{3} \mathrm{CH}_{2} \mathrm{COOH}$, Sisco Research Laboratories, India), methyl paraben ( methyl-p-hydroxybenzoate, Loba-Chemie, India), Ethanol ( Merck Specialities Private Limited ,India), Lactic acid ( $\mathrm{CH}_{3} \mathrm{CH}(\mathrm{OH}) \mathrm{COOH}$, Sisco Research Laboratories, India), orcein( for microscopy, Loba-Chemie, India) were used for this study.

Fly culture:-

Five adult male and five adult female Drosophila melanogaster were allowed to mate in each $50 \mathrm{ml}$ glass culture vial with $10 \mathrm{ml}$ standard Drosophila culture medium containing agar, maize powder, molasses, yeast, propionic acid and antimicrobial agent methyl paraben with varying concentrations $(100 \mathrm{mg} / \mathrm{L}, 200 \mathrm{mg} / \mathrm{L}, 300 \mathrm{mg} / \mathrm{L}, 400 \mathrm{mg} / \mathrm{L}$, $600 \mathrm{mg} / \mathrm{L})$ of $\mathrm{Pb}\left(\mathrm{NO}_{3}\right)_{2}$. Control vials also contained five male and five female mating partners and the medium included all the above mentioned ingredients except for $\mathrm{Pb}\left(\mathrm{NO}_{3}\right)_{2}$. Five repetitions in each concentration of $\mathrm{Pb}\left(\mathrm{NO}_{3}\right)_{2}$ and control were used in this study. All the cultures vials were maintained at $25^{\mathrm{O}} \mathrm{C}$ in a B.O.D. After the initial appearance of a pupa in a culture vial, the breeding male and female flies were removed from that culture vials. In the same way mating partners were removed from other culture vials also.

\section{Preparation of polytene chromosomes of Drosophila for microscopic examinations:-}

Mature third instar larvae exposed to different concentrations of $\mathrm{Pb}\left(\mathrm{NO}_{3}\right)_{2}$ as well as control larvae were used for the isolation of polytene chromosomes. Larvae were harvested from culture vials, washed thoroughly in ringer solution to remove food materials and transfered on a grooved slide in ringer. A pair of salivary glands was dissected out from each larva under a dissecting microscope. Three pairs of such dissected glands were removed from third instar larvae exposed to each concentration of $\mathrm{Pb}\left(\mathrm{NO}_{3}\right)_{2}$ separately on a glass slide. Aceto-alcohol (1:3 ratio of glacial acetic acid and ethanol) was added to them drop wise for two minutes for fixation. After fixation, the glands in slides were stained with aceto-orcein for 10-15 minutes keeping them covered under a petridish. Following this, stain was carefully absorbed by a filter paper from the slides and glands were washed with a few drops of $50 \%$ acetic acid to remove any excess stain. Excess acetic acid was absorbed with a filter paper and 1-2 drops of lacto- 
orcein was added on the glands on glass slides. A cover glass was mounted over the glands and the whole slide was wrapped with filter paper to remove excess mounting material. Uniform and gentle thumb pressure was applied on the cover glass above the glands to squash them for proper spreading of polytene chromosomes.

\section{Data Analyses:-}

Data were analyzed in following three aspects:

1. Assessment of intermediate time (in hour) needed for stage-specific development: It was done by counting the number of hours required for the developing flies to reach a particular stage of development considered under our study i.e. third instar larva, pupa or adult from the time (hour 0) during which parental male and female flies were released into each culture vial for mating.

2. Assessment of the number of representatives individuals of pupal and adult stages: It was done by counting the total number of pupae and young adults appeared in each culture vial till 100 hours from the initial time of their appearances.

3. Assessment of chromosomal rearrangements: It was performed by high resolution microscopic (Olympus Microscope, Japan, Model L-200A) examination of the prepared polytene chromosomes in the glass slides obtained from third instar larvae of control and test groups. Photographs of selected chromosomal aberrations were taken at X100 magnification by a camera (Nikon, Japan, Model- EH-53).

\section{Statistical Analyses:-}

Numerical values were expressed as the mean \pm standard deviation (SD). ' $t$ ' test was performed to i) determine the deviation of the test group, if any, from the controls with respect to number of hours required for initial appearances of third inster larvae, pupae and young adults from hour ' 0 ' and ii) deviation of the test group, if any, from the controls with respect to number of representative individuals of developmental stages like pupa and adults upto 100 hours from the initial time of appearances.

\section{Results:-}

Assessment of intermediate time needed for stage-specific development:-

Figure 1 shows that as compared to controls, number of hours needed for the initial appearances of third instar larvae, pupae and young adults from hour ' 0 ' increased significantly and in a dose dependent manner from $\mathrm{Pb}(\mathrm{NO})_{2}$ concentration of $300 \mathrm{mg} / \mathrm{L}$, followed by $400 \mathrm{mg} / \mathrm{L}$ and $600 \mathrm{mg} / \mathrm{L}$.. Levels of significance of deviations in developmental time course in response to the exposure of flies to these three concentrations of $\mathrm{Pb}\left(\mathrm{NO}_{3}\right)_{2}$ gives the $p$ value $\leq 0.05$, which is under accepted level of statistical significance at $95 \%$ confidence level and 5 degrees of freedom. Compared to controls no significant difference in the appearance of these three stages of development was observed owing to the exposure of the flies to $\mathrm{Pb}\left(\mathrm{NO}_{3}\right)_{2}$ concentration of 100 and $200 \mathrm{mg} / \mathrm{L}$, as all of which showed $\mathrm{p}$ values $>0.05$.

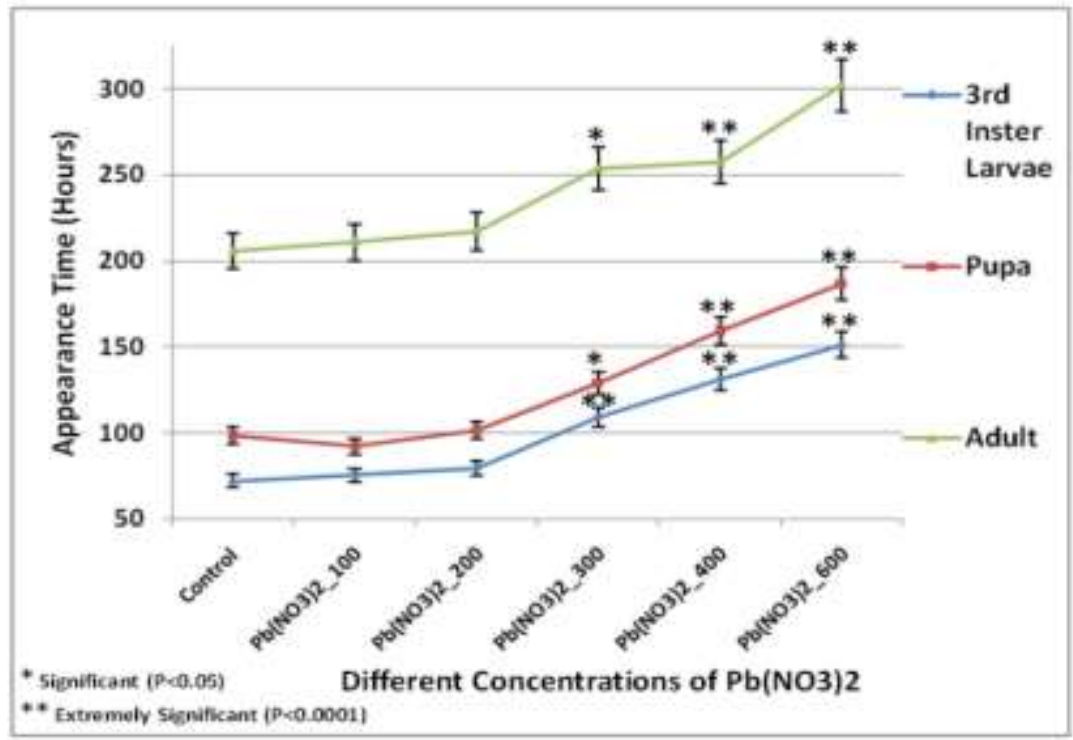

Figure 1:- Time course of developmental stages of Drosophila melanogaster exposed to varying concentrations of $\mathrm{Pb}\left(\mathrm{NO}_{3}\right)_{2}$. Data are represented as the number (Mean $\left.+/-\mathrm{SD}\right)$ of hours required for initial appearances of the 
particular stages of development of Drosophila melanogaster from ' 0 ' hour during which adult male and female flies were released into the control and test culture vials for mating. $(* \mathrm{p}<0.05$, $* * \mathrm{p}<0.0001)$

\section{Assessment of the number of representative individuals of pupal and adult stages:-}

Examination of the number (mean +/- SD) of pupae and adults generated upto 100 hours from their initial time of appearances, as shown in Fig 2, reveals that compared to controls, the fly cultures exposed to varying concentration of $\mathrm{Pb}\left(\mathrm{NO}_{3}\right)_{2}$, showed dose dependent significant reduction in their number starting from $\mathrm{Pb}\left(\mathrm{NO}_{3}\right)_{2}$ concentration of $200 \mathrm{mg} / \mathrm{L}$. However, highly significant reduction ( $p$ value $\leq 0.0001$ ) in the number of representative individuals of both these stages of development were noticed from $\mathrm{Pb}\left(\mathrm{NO}_{3}\right)_{2}$ concentration of $300 \mathrm{mg} / \mathrm{L}$ onwards reaching the hallmark at $600 \mathrm{mg} / \mathrm{L}$ where the population of both pupae and emergent adults were drastically reduced by more than 50\% compared to such populations of control cultures. No significant difference in the pupa and emergent adult populations from controls was observed owing to the exposure of the flies to $\mathrm{Pb}\left(\mathrm{NO}_{3}\right)_{2}$ concentration of 100 $\mathrm{mg} / \mathrm{L}$. The percent reduction of population of pupae and emergent adults compared to controls in response to exposure to $\mathrm{Pb}\left(\mathrm{NO}_{3}\right)_{2}$ concentration from $200-600 \mathrm{mg} / \mathrm{L}$ are shown in the Table 1 .

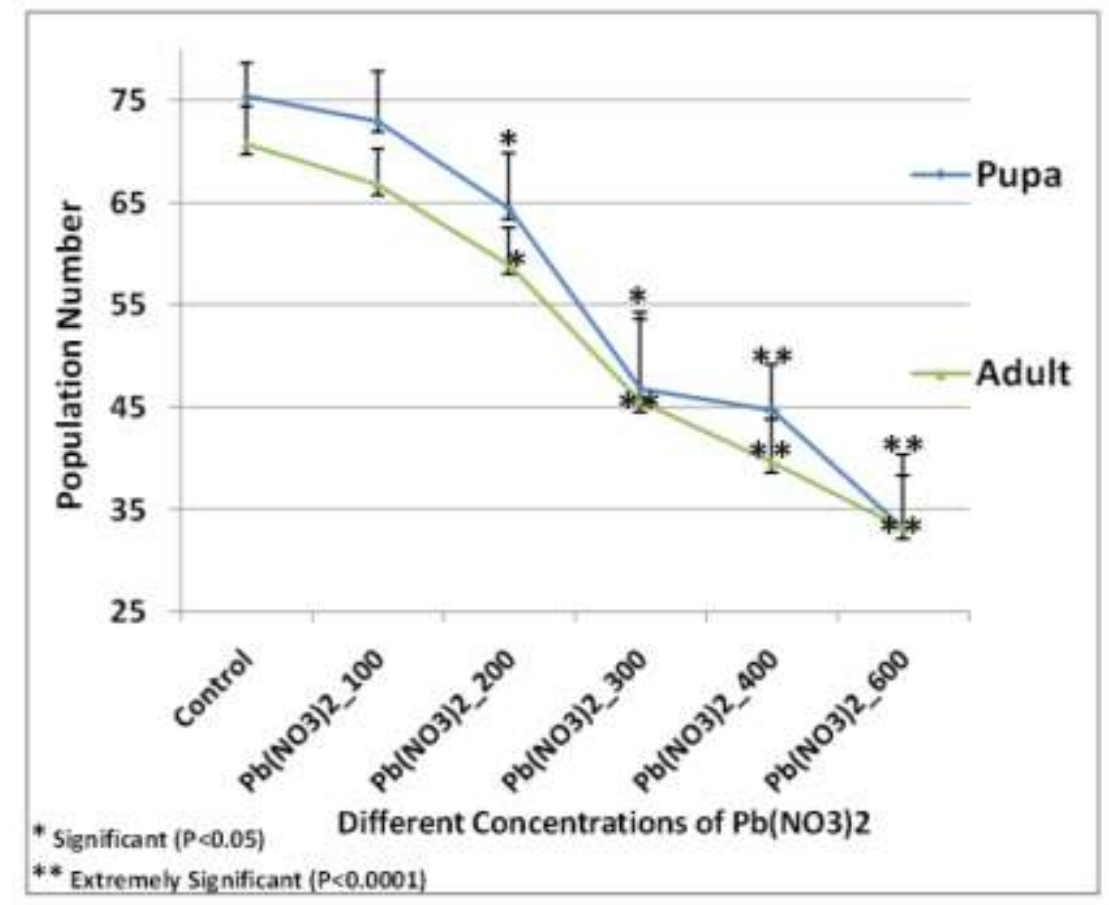

Figure 2:-Population data of Drosophila melanogaster exposed to varying concentrations of $\mathrm{Pb}\left(\mathrm{NO}_{3}\right)_{2}$. $\mathrm{Data}$ are represented as the number (Mean $+/-\mathrm{SD}$ ) of pupae and young adults appeared up to 100 hours from their initial time of appearances in control and test culture. $(* p<0.05, * * p<0.0001)$

Table1:-Percent reduction of population of pupae and emergent adults compared to controls in response to exposure to varying $\mathrm{Pb}\left(\mathrm{NO}_{3}\right)_{2}$ concentration from $200-600 \mathrm{mg} / \mathrm{L}$

iii. Assessment of chromosomal rearrangements:

Polytene chromosomes prepared from the third instar larvae of the flies exposed to $\mathrm{Pb}\left(\mathrm{NO}_{3}\right)_{2}$ at concentrations of $300 \mathrm{mg} / \mathrm{L}, 400 \mathrm{mg} / \mathrm{L}$ and $600 \mathrm{mg} / \mathrm{L}$ exhibited a number of chromosomal rearrangements like asynapsis (Fig. 3, Fig 4), ectopic pairing (Fig. 5), constriction (Fig3) and fusion (Fig. 6, Fig. 7), etc. Larvae harvested from any culture

\begin{tabular}{|c|c|c|}
\hline Concentration of $\mathrm{Pb}(\mathrm{NO3}) 2$ & $\begin{array}{l}\text { Percent (\%) reduction of pupal } \\
\text { population }\end{array}$ & $\begin{array}{l}\text { Percent (\%) reduction of emergent } \\
\text { adult population }\end{array}$ \\
\hline $200 \mathrm{mg} / \mathrm{L}$ & $\mathbf{1 4 . 5 8}$ & $\mathbf{1 6 . 6 6}$ \\
\hline $300 \mathrm{mg} / \mathrm{L}$ & $\mathbf{3 7 . 9 3}$ & $\mathbf{3 5 . 5}$ \\
\hline $400 \mathrm{mg} / \mathrm{L}$ & $\mathbf{4 0 . 5 8}$ & $\mathbf{4 4 . 0 6}$ \\
\hline $600 \mathrm{mg} / \mathrm{L}$ & $\mathbf{5 5 . 9 6}$ & $\mathbf{5 3 . 1 0}$ \\
\hline
\end{tabular}


exposed to $\mathrm{Pb}\left(\mathrm{NO}_{3}\right)_{2}$ at concentrations lesser than $300 \mathrm{mg} / \mathrm{L}$ and control culture exhibited very negligible abnormalities. Frequencies of chromosomal rearrangements in larval polytene chromosomes was observed highest at $\mathrm{Pb}\left(\mathrm{NO}_{3}\right)_{2}$ concentrations of $600 \mathrm{mg} / \mathrm{L}$ followed by $400 \mathrm{mg} / \mathrm{L}$ and $300 \mathrm{mg} / \mathrm{L}$.

Figure 3:- Asynapsis and constriction of polytene chromosome in response to the $\mathrm{Pb}\left(\mathrm{NO}_{3}\right)_{2}$ concentration $600 \mathrm{mg} / \mathrm{L}$

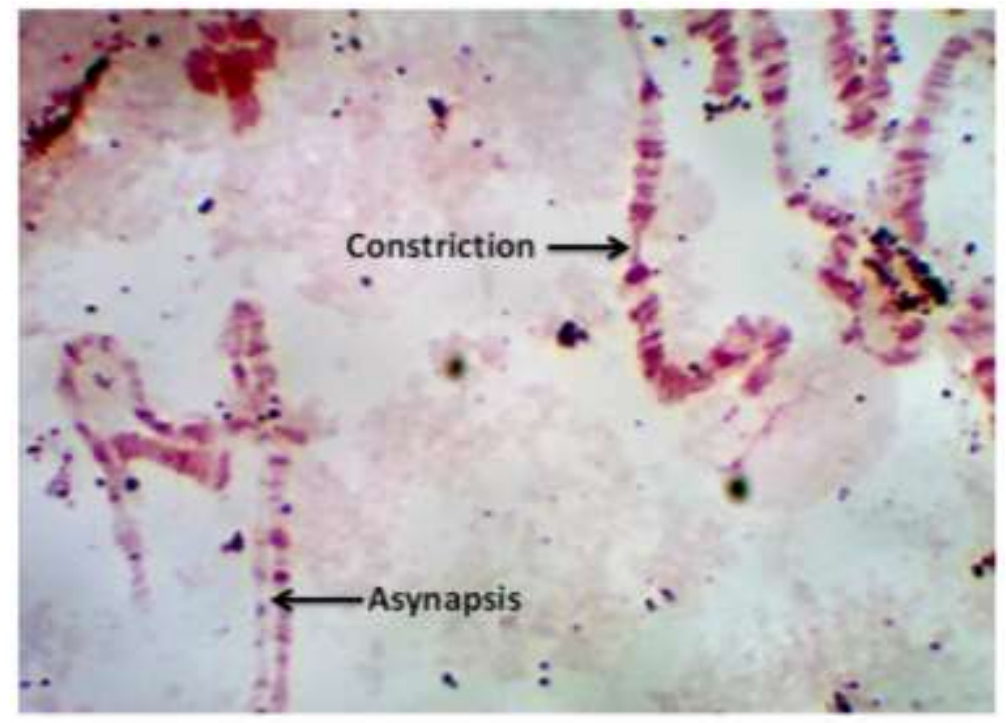

Figure 4:- Asynapsis of polytene chromosome in response to the $\mathrm{Pb}\left(\mathrm{NO}_{3}\right)_{2}$ concentration $400 \mathrm{mg} / \mathrm{L}$

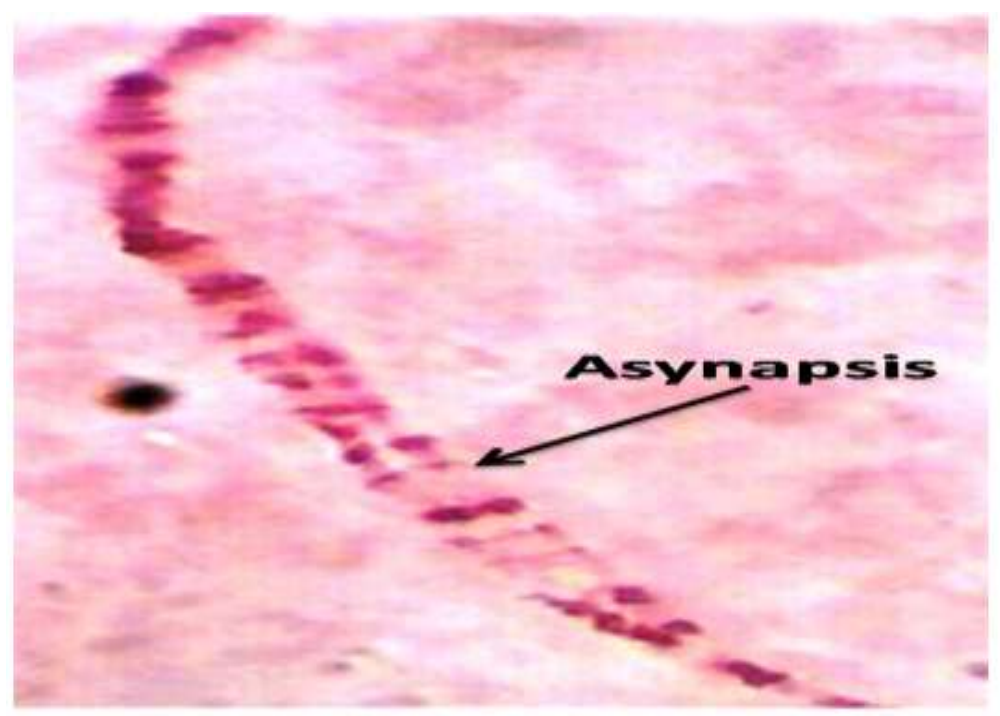


Figure 5:- Ectopic pairing of polytene chromosome in response to the $\mathrm{Pb}\left(\mathrm{NO}_{3}\right)_{2}$ concentrations $600 \mathrm{mg} / \mathrm{L}$

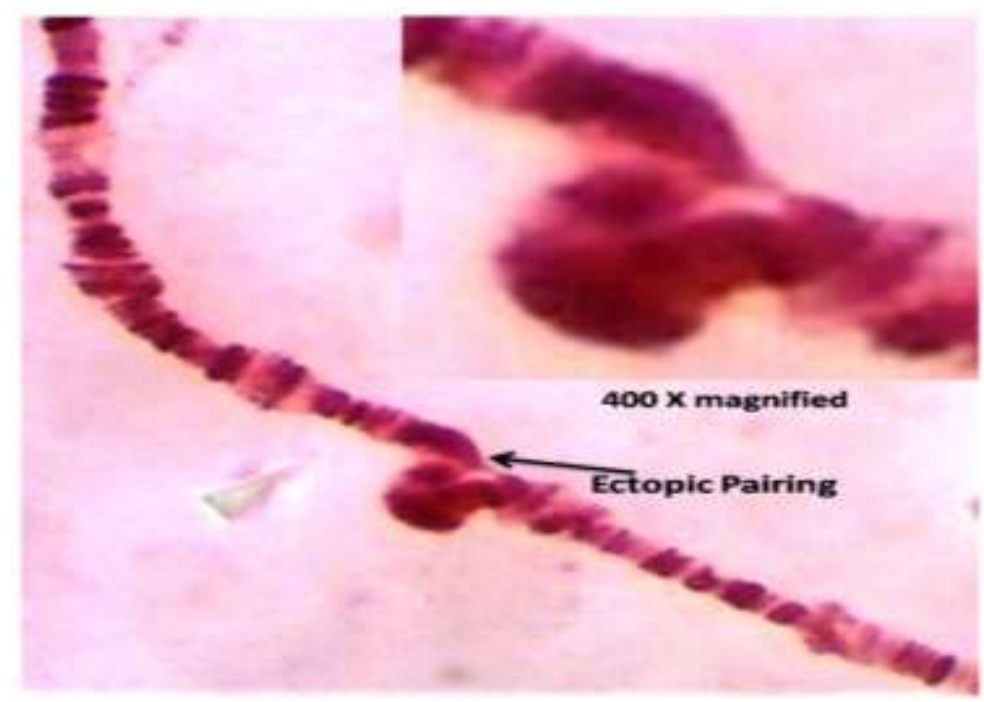

Figure 6:-Fusion of polytene chromosome in response to the $\mathrm{Pb}\left(\mathrm{NO}_{3}\right)_{2}$ concentrations $400 \mathrm{mg} / \mathrm{L}$

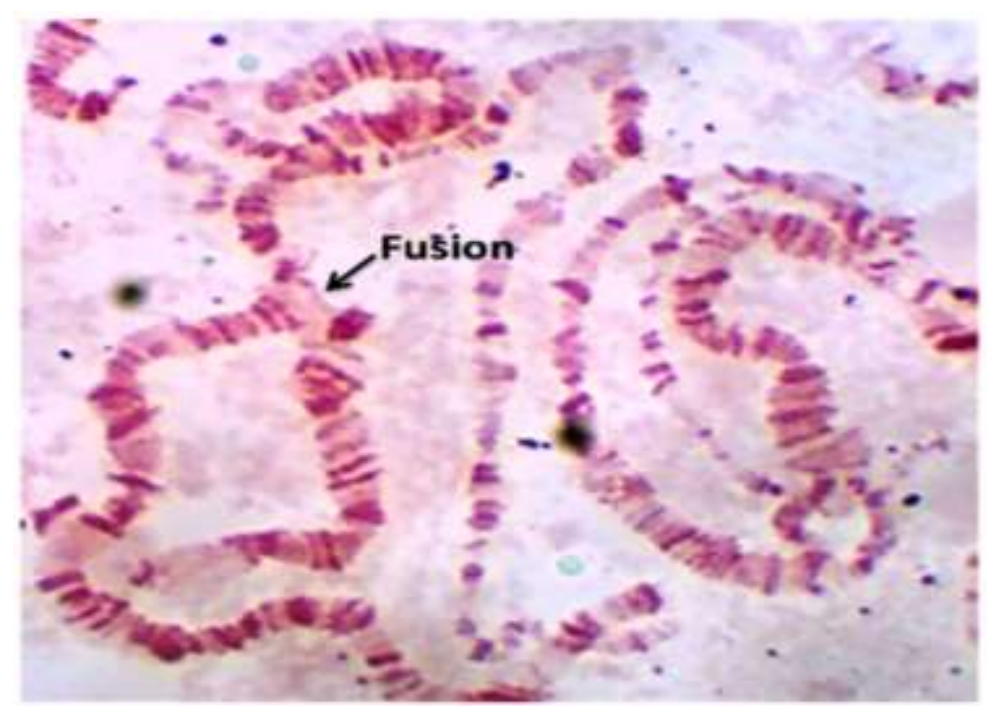


Figure 7:-Fusion of polytene chromosome in response to the $\mathrm{Pb}\left(\mathrm{NO}_{3}\right)_{2}$ concentrations $600 \mathrm{mg} / \mathrm{L}$

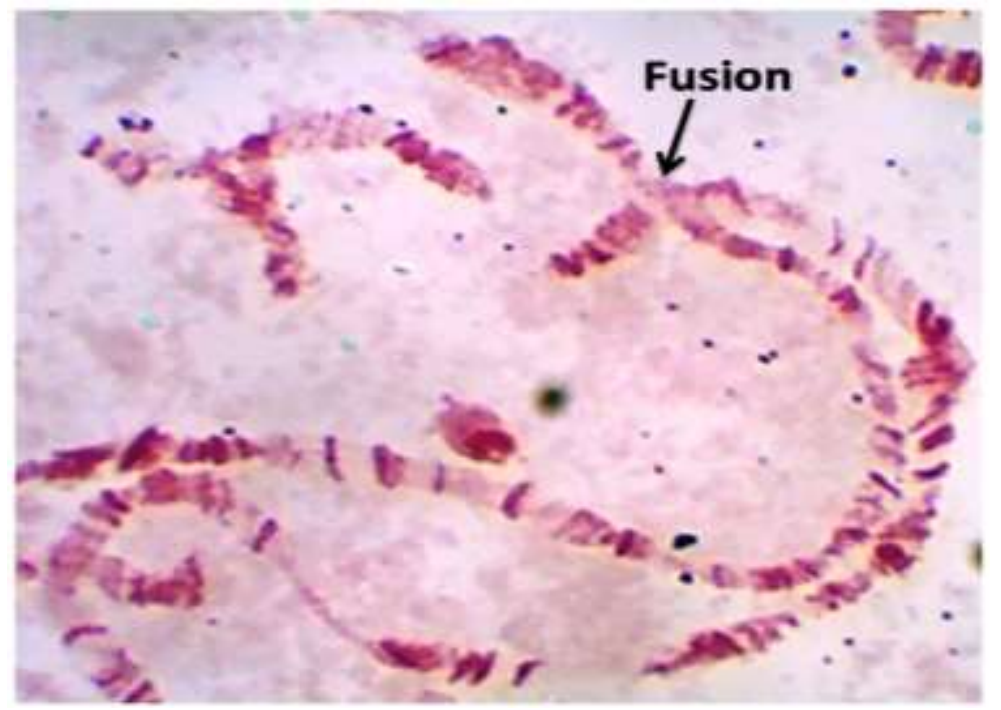

\section{Discussion:-}

In this present study we have used Drosophila melanogaster for our experiments as it is an important model for developmental biology (Sahai-Hernandez, 2012) and toxicological studies ( Hirschet al, 2003; Rand et al, 2009; Rand et al, 2014). As human being exhibit substantial genetic similarities with this dipteran fly it is expected that effects of toxicants on the development of this fly may reflect analogous situations in human. We have observed that, compared to controls, exposure of flies to $\mathrm{Pb}\left(\mathrm{NO}_{3}\right)_{2}$ caused significant delay in the initial appearances of the individuals of any particular stage of development as well as caused reduction in number of pupae and emerging adults at the heavy metal salt concentration of $300 \mathrm{mg} / \mathrm{L}$ and above. These negative outcomes in development were culminated when the flies were exposed to this heavy metal salt at a concentration of $600 \mathrm{mg} / \mathrm{L}$ in which number of emerging adults, upto 100 hours from their initial appearances, reduced by more than 50\% in comparison to controls .After an extensive search of published data we could find only one similar report (Safaee et al. 2014) regarding the dose dependent effect of $\mathrm{Pb}\left(\mathrm{NO}_{3}\right)_{2}$ on the development of Drosophila melanogaster. Results of this study showed that, significant delay in the appearances of individuals of different developmental stages as well as significant inhibition of the number of pupae and emerging adults in response to $\mathrm{Pb}\left(\mathrm{NO}_{3}\right)_{2}$ exposure occurred at a concentration as low as $50 \mathrm{mg} / \mathrm{L}$, compared to controls. However, in our case, the least concentration of $\mathrm{Pb}\left(\mathrm{NO}_{3}\right)_{2}$ needed for inducing significant delay in appearances of different developmental stages and significant reduction of pupal and emerging adult numbers were $300 \mathrm{mg} / \mathrm{L}$ and $200 \mathrm{mg} / \mathrm{L}$ respectively. Heavy metal detoxification is mediated in Drosophila by protein metallothioneins which is similar to mammals. However, the ability of detoxification of this protein is limited and it fails to detoxify highly concentrated heavy metals inside the body (Safaee et al. 2014). As compared to the study mentioned above, eggs and larvae of our experiments tolerated higher concentrations of $\mathrm{Pb}\left(\mathrm{NO}_{3}\right)_{2}$.. The differences of tolerance of $\mathrm{Pb}\left(\mathrm{NO}_{3}\right)_{2}$ may be due to the differences in strains of Drosophila melanogaster used for experiments by us and the other group as it has been reported that strain differences of Drosophila had led to differences in their tolerance of chemicals such as alcohol (Bokor et al. 1997). As DNA exhibits potential sites vulnerable to chemical and physical agents, degree of chromosomal abberations induced by such agents may imply their mutagenic potentiality. Use of polytene chromosome for studying mutagenic potential of different agents gives us an added advantage as they allow us to see deleterious effects on chromosomes in a magnified way due to the gigantic size of this chromosome (Chaudhry et al, 2006). It has been proposed that lead exposure can induce chromosomal aberration by DNA breakage and inhibition of repair enzymes ( Uysal, 1997). Very limited data is available regarding the effect of any lead salt exposure on the polytene chromosomal architecture in Drosophila larvae. We could find one report in which exposure of lead acetate caused abberations like ectopic pairing, breaks, asynapsis and constriction in polytene chromosome of the third instar larvae of Drosophila melanogaster (Uysal, 1997). In our present study a number of chromosomal rearrangements like ectopic pairing, asynapsis, fusion, constriction etc. were observed in the polytene chromosomes of the third instar larvae of this fly exposed at concentrations of $\mathrm{Pb}\left(\mathrm{NO}_{3}\right)_{2}$ ranging from 300-600mg/l. Asynapsis i.e. the failure of pairing of homologs of polytene chromosome were observed in larvae exposed to $\mathrm{Pb}\left(\mathrm{NO}_{3}\right)_{2}$ at both 400 and $600 \mathrm{mg} / \mathrm{L}$ 
concentrations. It has been suggested that homologs are drawn together through the contraction of fibrillar connectors (Holliday, 1968) or bundles of microfilaments (Bennett et al, 1979) Thus it can be speculated that asynapsis in larval polytene chromosomes may be caused by the heavy metal induced distortion of these fibrillar connectors and microfilaments. It has been proposed that (Fung et al, 1998) that in Drosophila melanogaster gene expression can be modulated by physical pairing. Asynapsis of homologs has shown to reduce the level of transcription of genes as it disrupt the trans-interaction (transvection) of enhancer and promoter elements that occurs during paired state (Goldsborough et al, 1996). Another important rearrangement that we have observed is the nonhomologous conjuction or ectopic pairing in polytene chromosomes of the larvae exposed to $\mathrm{Pb}\left(\mathrm{NO}_{3}\right)_{2} \operatorname{concentration}$ of 400 and $600 \mathrm{mg} / \mathrm{L}$. In ectopic pairing certain regions of a chromosome show toroidal structure with a tendency to establish linkage through heterochromatin threads between two separated homologous nucleotides sequences. It is possible that due to ectopic pairing discrete homologous nucleotide sequences in a chromosome may rejoin to produce a new gene sequence (Chaudhry et al, 2006). We speculate that such newly formed gene sequence might code for an unusual protein not normally found in Drosophila larvae and inhibited the normal development of the fly. We have observed other rearrangements like constriction and fusion of polytene chromosome in third instar larvae exposed to $\mathrm{Pb}\left(\mathrm{NO}_{3}\right)_{2}$ concentration of 300,400 and $600 \mathrm{mg} / \mathrm{L}$. Constriction in chromosomes represent the fragile sites that arise due to the inhibition of DNA replication and may undergo breakage (Zlotorynski et al, 2003). As heavy metals are regarded as the sources of replication stresses (Sasi and Weinreich, 2016), $\mathrm{Pb}(\mathrm{NO})_{2}$ can induce chromosomal constrictions that may ultimately repress the gene expressions. Fusion of chromosomes might distort the normal gene sequences and negatively affected their expressions. It has been observed in our present study that the onset of negative influences in the development of the fly corresponded the $\mathrm{Pb}\left(\mathrm{NO}_{3}\right)_{2}$ concentration that initiated the larval chromosomal rearrangements also. We speculate that $\mathrm{Pb}\left(\mathrm{NO}_{3}\right)_{2}$ at higher concentrations escaped the natural detoxification ability of the fly and hindered the normal expression of genes required for development due to deleterious rearrangement of chromosomes that probably disrupted interactions of controlling elements of gene expressions or simply changed the normal gene sequences. Due to extensive genetic homology between human and Drosophila melanogaster, it is possible that maternal exposure of $\mathrm{Pb}\left(\mathrm{NO}_{3}\right)_{2}$ at higher concentrations during human pregnancy can bring about similar detrimental effects on the chromosomes of developing embryo leading to deleterious effect on child birth.

\section{Conclusion:-}

It can be concluded that, heavy metal exposure during development impose serious chromosomal abnormalities that may interfere the normal developmental gene expression, which is manifested as abnormal development.

\section{Referneces:-}

1. Abadin, H., Ashizawa, A., Stevens, Y., Llados, F., Diamond, G., Sage, G., Citra, M., Quinones. A., Bosch, S.J. and Swarts SG. (2007): Health effects. In: Toxicological Profile for Lead. Agency for Toxic Substances and Disease Registry (US). Atlanta (GA).

2. Abdullahi, M. S. (2013 ): Toxic effects of lead in humans: an overview.Glo.1 Adv. Res. J. Env. Sci. Toxicol,2(6) : 157-162

3. Agrawal, P., Mittal, A., Kumar, M. and Tripath, S. K . (2009): A comprehensive review of environmental exposure of Lead and its toxicity. J. Ind. Acad. Forensic Med, 31(3): 299-303.

4. Amadi,C.N., Igweze, Z.N. and Orisakwe, O.E.(2017). Heavy metals in miscarriages and stillbirths in developing nations. Middle East FertilSoc J, 22(2): 91-100.

5. Assi, M.A., Hezmee, M.N.M., Haron A.W., Sabri, M.Y.M. and Rajion , M.A.(2016).The detrimental effects of lead on human and animal health. Vet World, 9(6): 660-671.

6. Bennett MD, Smith JB, Simpson S, Wells B. (1979). Intranuclearfibrillar material in cereal pollen mother cells. Chromosoma, 71:289-332.

7. Bokor, K. andPecsenye, K. (1997) Strains of Drosophila melanogaster differ in alcohol tolerance. Hereditas, 126 (2): 103-113.

8. Chaudhry, A., Anand,P.K.,Geeta.,Singh.S, and Lovleen. ( 2006). Ectopic pairing of the intercalary heterochromatin in the organophosphate pesticide treated mosquito chromosomes (Culcidae: Diptera). Cytologia, 71(4): 431-437.

9. Fung, J.C., Marshall, W.F.,Dernburg, A., Agard, A.D. and John W. Sedat. (1998) . Homologous chromosome pairing in Drosophila melanogaster proceeds through multiple independent initiations. J. Cell Biol., 141(1): 520 
10. Goldsborough, A.S. and Kornberg, T.B. (1996). Reduction of transcription by homologue asynapsis in Drosophila imaginal discs.Nature, 381(6585): 807-810.

11. Haq, R., M. Khan, M.F. and Haq, E.(2011).Adverse Effect of lead acetate on Drsophila melanogaster. J. Basic \& Appl. Sci, 7(2): 15-163.

12. Hirsch HV, Mercer J, Sambaziotis H, Huber M, Stark DT, Torno-Morley T, Hollocher K, Ghiradella H, Ruden DM. (2003). Behavioral effects of chronic exposure to low levels of lead in Drosophilamelanogaster. Neurotoxicology, 24: 435-442.

13. Holliday, R. (1968). Genetic recombination in fungi. In Replication and Recombination of Genetic Material. W.J. Peacock and R.D. Brock, editors. Australian Academy of Science, Canberra. 157-174.

14. Lead and lead compounds.Report on carcinogens, (2016). https://ntp.niehs.nih.gov/ntp/roc/content/profiles/lead

15. Lead poisoning - Symptoms and causes - Mayo Clinic. http://www.mayoclinic.org/diseases-conditions/leadpoisoning/symptoms-causes/dxc-20275054

16. Lu, L., Cheng, H., Liu, X., Xie, J., Li, Q. and Tan Zhou, T. (2015): Assessment of regional human health risks from lead contamination in Yunnan province, southwestern China. Plos one, 10(4): e0119562. Published online 2015 Apr 20. doi: 10.1371/journal.pone.0119562.

17. Nanda Kumar Sasi, Michael Weinreich(2016): DNA replication Checkpoint Signalling. In: Daniel L. Kaplan (Ed) The Initiation of DNA Replication in Eukaryotes. Springer 2016Switzerland.

18. Pandey, U.B. and Nichols, C.D. (2011). Human disease models in Drosophila melanogaster and the role of the fly in therapeutic drug discovery. Pharmacol. Rev, 63(2): 411-436

19. Rand MD, Dao JC, Clason TA. ( 2009). Methylmercury disruption of embryonic neural development inDrosophila. Neurotoxicol30: 794-802.

20. Rand MD, Montgomery SL, Prince L, Vorojeikina D. (2014). Developmental toxicity assays using the Drosophila model. CurrProtocToxicol59: 1.12.1-1.12.20.

21. Safaee, S.,MasoudFereidoni, A., Mahadavi-Shahri,N., Haddad, F and Mirshamsi, O.(2014). Effects of lead on the development of Drosophila melanogaster.Period. Biol, 116(3): 259-265.

22. Sahai-Hernandez P, Castanieto A, Nystul TG. (2012). Drosophila models of epithelial stem cells and their niches. Wiley Interdiscip Rev DevBiol, 1: 447-457.

23. Tong, S., Yasmin E. von Schirnding, Y.E.V. and Prapamontol, T. (2000 ): Environmental lead exposure: a public health problem of global dimensions. Bull. World Health Organ,78 (9): 1068-1077.

24. Uysal, H. (1997). Induction of chromosomal aberrations in polytene chromosomes of Drosophila melanogaster by lead acetate. Cytologia, 62(3): 213-217.

25. Wani,A.L., Ara, A. and UsmanI, J.A. (2015): Lead toxicity: a review. Interdiscip. Toxicol., 8(2): 55-64

26. Zlotorynski, E., Rahat, A.,Skaug, J., Ben-Porat, N.,Ozeri, E.,Hershberg,R., Levi, A., SScherer, S.W., Margalit, H. and BatshevaKerem. (2003).Molecular Basis for Expression of Common and Rare Fragile Sites. Mol Cell Biol, 23(20): 7143-7151. 